immunosurgery PGCs

1 TITLE

2

\title{
3 Effective Cell Immunoablation in Undisrupted Developing Avian Embryos
}

4 Maríacruz López-Díaz ${ }^{\text {ał }}$, Julia Buján-Varela ${ }^{\text {b }}$ and Carlos Cadórniga-Valiño ${ }^{a}$

anstituto Nacional de Investigación y Tecnología Agraria y Alimentaria (INIA). 28040 Madrid - Spain ‡Author for correspondence: (lopez.maria@inia.es )

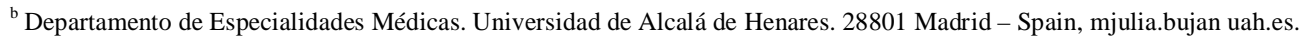


bioRxiv preprint doi: https://doi.org/10.1101/091116; this version posted December 2, 2016. The copyright holder for this preprint (which was not certified by peer review) is the author/funder. All rights reserved. No reuse allowed without permission.

immunosurgery PGCs

7 SUMMARY STATEMENT

8 An immunosurgery procedure is described that yields an almost complete ablation of 9 primordial germ cells in early developing chick embryos, thus increasing the expected 10 rates of chimerism when foreign PGCs are grafted onto these embryos 
immunosurgery PGCs

\section{ABSTRACT}

13 In birds the construction of germline chimeras by grafting exogenous primordial germ cells

14 (PGCs) during embryonic development is feasible since they migrate to the gonads through

15 the blood. Up to date, the efficiencies are highly variable, in part dependent on the destruction

16 of endogenous PGCs in the recipient embryo. We show an almost complete ablation of the

17 endogenous PGCs in stage $\mathrm{X}$ embryos using a baby rabbit serum (BRS), with previous

18 cellular signaling by specific antibodies (SSEA1). The application of the treatments, either on

19 epiblast or subgerminaly, produced the reduction of the PGCs in the embryos in a dose

20 dependent manner. No malformations or damages were detected in the treated embryos.

21 However, subgerminal injection of this cocktail produced a massive cellular destruction in all

22 embryos. Therefore, sequential application is a selective and effective method to produce

23 receptor embryos. Nevertheless, it can also be highly destructive if the mixture is applied

24 locally, this could be useful in the treatment of malignancies.

26 Keywords: PGCs, immunosurgery, chicken embryos. 
immunosurgery PGCs

29 Very few studies have been done "in vivo" since 1975 when Solter and Knowles coined the 30 term of "immunosurgery". These authors were able to ablate the trophectoderm cells in mouse 31 embryos by using antibody and complement. In 2007 Chen and Melton by using antibodies 32 against red blood cells and heterologous guinea pig serum as a source of complement, 33 achieved successfully isolation of the inner cell mass in human embryos. Also Gerhart et al. 34 developed an efficient ablation procedure of two epiblast cell types with neuronal and 35 muscular epitopes by using specific antibodies and baby rabbit serum (BRS) in stage $\mathrm{X}$ 36 chicken embryos (Gerhart et al 2008, 2010).

On the other hand, in birds it is needed to develop new assisted reproduction procedures since avian oocytes and embryos are organized as an extremely precise biological structure, the egg. This complex assembly of oocyte/embryo does not stand freezing as is the case of mammalian embryos. Every aspect of the fertilized egg ( $\mathrm{pH}$ of the different compartments, gas permeability, density relations and floatability, access to the different layers of nutrients, etc) is finely adjusted (Stern 1991, Lopez-Diaz et al. 2016). However, avian embryo has morphophysiological peculiarities which allow the spread of a genotype or a specific lineage from the precursor cells of sperm and oocytes, the primordial germ cells (PGCs), which can be cryopreserved ex-situ. This assisted reproduction procedure involves the construction of germline chimeras by grafting, during embryonic period, PGCs of the desired lineage on a recipient embryo of a different strain (van de Lavoir 2006).

50 The inactivation of the recipient's germ line has been used as a strategy to improve the degree 51 of germinal chimerism. For decades, the commonly used methods have been irradiation 52 (Maeda et al, 1998, Carsience et al, 1993; Kino et al 1997; Speksnijder and Ivarie, 2000; Lia 
immunosurgery PGCs

53 et al, 2001; Nakamura et al, 2012) or administration of cytotoxic agents (Hemsworth \&

54 Jackson 1963; Reynaud 1977; Mozdziak et al 2006; Song et al, 2005; Petitte et al 1990;

55 Bresler at al., 1994; Aige Gil V and Simkiss K 1991, Naito et al. 2015). Both are effective, but 56 completely unspecific, equally affecting all populations of embryonic cells, damaging the

57 viability of the recipient embryo. In fact, the results usually achieved have an extremely high

58 variability in the transmission rates of the grafted germline (2.9-100\%), whether the

59 endogenous PGCs are inactivated (Naito et al. 2015) or not (van de Lavoir 2006, White et al.

60 2015), this means that the procedure is not under control.

62 The origin and migration of avian PGCs have been well characterized (Dubois 1969; Kuwana 63 and Fujimoto, 1984; Muniesa and Dominguez, 1990) since first described by Swift (1914). It

64 has been estimated that the number of PGCs at oviposition (stage X embryo) is 100-120. Such

65 a reduced number of cells and the high potential of developmental plasticity make this

66 developmental stage the best time for the elimination of endogenous PGCs.

68 On the other hand, the combined cytolytic action of antibodies and complement has been well

69 known for over a century (Wiemann 1994) and has been applied with different therapeutic

70 and experimental purposes. In rabbits previously grafted with cancer cells (Kalfayan \& Kidd,

71 1953) the combination of serum complement with antibodies against Brown-Pearce

72 carcinoma cells achieved effective inhibition of tumor growth. Nowadays, one of the best

73 treatments against cancer is the use of antibodies, with over 20 of different nature approved by

74 various regulatory agencies (Macor \& Tedesco 2007). As a consequence, in the last few

75 decades the antibody-complement actions have been deeply investigated. It is known that

76 complement modulates the complement dependent cytotoxicity (CDC) and antibody

77 dependent cytotoxicity (ADCC). However, complement can have opposite effects; it can 
immunosurgery PGCs

78 favor CDC and inhibit ADCC. Our understanding of the mechanisms involved when antibody

79 and complement are acting together is still in its infancy (Rogers et al. 2014).

81 Like many malignant neoplastic cells, PGCs have a glycocalix rich in trisaccharide Gal (1-

82 4), Fuc $\alpha$ (1-3)-GlcNAcß1-R4 which is recognized by antiSSEA1. In fact, antiSSEA1 has

83 been widely used to enrich selectively PGCs from stage X embryos (Etches 1998) and

84 gonocytes from embryos of 5days, stage 27 (Mozdziak 2006).

86 Therefore, the objective of this study was to create viable chick embryos without endogenous

87 PGCs, taking advantage of the complement dependent cytolysis (CDC). We used antiSSEA1,

88 Ig M monoclonal antibody, together with baby rabbit serum (BRS) as a source of complement

89 to induce a selective ablation of the PGCs in stage $\mathrm{X}$ chicken embryos. These chicken

90 embryos could be used as receptors for unique exogenous PGCs.

\section{RESULTS}

\section{"In vitro" cytolysis of avian blastoderm cells}

94 Competition tests of dispersed blastodermal cells with haemolytic system (HS) composed by

95 sheep red blood cell (SRBCs) and haemolysin in gelatine-Veronal buffer with $\mathrm{Ca}^{2+} \mathrm{Mg}^{2+}$.

96 Haemolytic complement activity measures the complement classical pathway in serum. Fifty

97 percentage of haemolytic complement activity $\left(\mathrm{CH}_{50}\right.$ or $\mathrm{Kd}=$ dissociation constant $)$ in

98 competition curves, measures serum haemolysis capacity in $\mathrm{SRBCs}$. $\mathrm{CH}_{50}$ is sensitive to any

99 reduction of the classical pathway components. Therefore, haemolysis absorbance of SBRCs

100 was evaluated (y-axis) with decreasing concentrations of baby rabbit serum (BRS) as a

101 complement source (x-axis), without antiSSEA1 (yellow line) and with antiSSEA1 1/100 
bioRxiv preprint doi: https://doi.org/10.1101/091116; this version posted December 2, 2016. The copyright holder for this preprint (which was not certified by peer review) is the author/funder. All rights reserved. No reuse allowed without permission.

immunosurgery PGCs

102 (blue line) in presence of blastodermal cells. Saturation curve with dispersed blastodermal

103 cells and antiSSEA1 1/100 revealed that, when blastodermal cells and antiSSEA1 were

104 present, the saturation was reached and that the $\mathrm{Kd}\left(\mathrm{CH}_{50}\right)$ was between $1 / 10$ and $1 / 100$

105 dilutions of BRS (Fig 1a). These dilutions were used for selective PGCs ablation studies. We

106 performed next experiments focused on dilutions of $1 / 00$ and $1 / 40$ for antiSSEA1 and BRS,

107 respectively.

108 Evaluation of cellular lysis with trypan blue after challenges with antiSSEA1 and BRS. In

109 isolated blastoderms the cellular lysis was evident in zona pellucida, where PGCs are

110 localized at this stage, while in control embryos none of the cells were stained (Fig 1b, A and

111 B).

Figure 1. 1a Saturation curve. Competition test with dispersed blastodermal cells and anti SSEA1 1/100. Haemolysis absorbance of sheep red blood cell (SBRC yaxis) with decreasing concentrations of baby rabbit serum (BRS) as a complement source ( $x$ axis). without antiSSEA1 (vellow line) and with antiSSEA1 1/100 (blue line). When blastodermal cells and antiSSEA1 were present the saturation was reached and the $\mathrm{CH}_{50}(\mathrm{Kd})$ was between $1 / 10$ and $1 / 100$ dilutions of BRS. Blastoderm cell suspensions from ten stage $X$ embryos were used in each saturation curve. 1b. Deposition of antiSSEA1 and baby rabbit serum to the dorsal side of epiblast and evaluation of cellular lysis with trypan blue. Chicken embryos stage $\times(A \times 4$ and $B$ x200), A) Control embryo treated with PBS and trypan blue exposed, none cell was stained by trypan blue (stereoscope Leica MZIII) B) Zona pellucida of one embryo challenged with antiSSEA 1 and baby rabbit serum, there are blue cells stained (NIKON, Eclipse TE300, inverted microscope). C) Deposition of the treatment to the dorsal side of epiblast. D) 24 hours embryo, developmental stage referred in the manuscript as "early development".
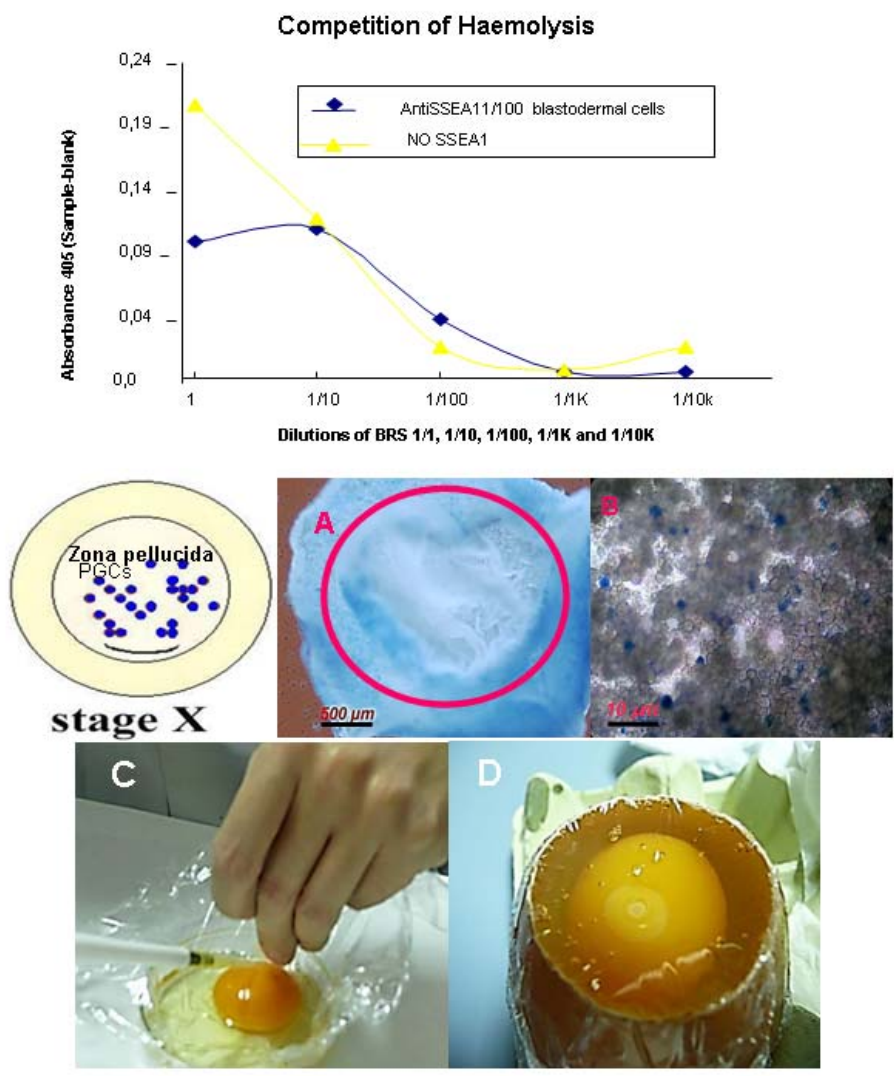
immunosurgery PGCs

113 Ex-ovo treatments applied to stage $\mathbf{X}$ embryos and incubated in surrogated egg shells

114 following Perry's system II

115 Embryonic development and number of PGCs in embryos treated with deposition of

116 antiSSEA1 and baby rabbit serum to the dorsal side of epiblast. Two times of embryo

117 development were evaluated, "early development" 24 hours after the application of the

118 treatment (Fig 1b C and D) and "late development" 3-day. The evaluation of embryonic

119 development revealed that the treatments and transfer manipulations did not affect neither

120 embryo "early development" (67-100\%) nor "late development" (56-90\%) in any of the

121 treated groups (AntiSSEA1 10/C+, 100/C+ and 1000/C+ groups) compared with control

122 groups (AntiSSEA1-/C- and AntiSSEA1-/C+), Table 1. The mean survival days was 4.7, as

123 expected in normal embryo development following Perry’s system II (Fig 2a), with no

124 significant differences between treatments. However, the number of PGCs detected was

125 decreased in treated (4, 2.7 and 4 PGCs in AntiSSEA1 10/C+, 100/C+ and 1000/C+ groups,

126 respectively) compared with control embryos (50 and 45 PGCs in AntiSSEA1-/C- and

127 AntiSSEA1-/C+) (Fig 2b). A total of 2,400 tissue sections were immunostained and 128 evaluated. 
immunosurgery PGCs

Table 1. Embryos distribution of "early" and "late development" when the treatment was deposited to the dorsal side of epiblast at stage X. "Early development" 24 hours after the application of the treatment, the embryo continues to advance. "Late development" at day fourth embryos with heartbeat and vascular tree well formed.

\begin{tabular}{lcccc}
\hline Treatment & & & & \\
AntiSSEA1/complement & $\mathbf{N}^{0}$ embryos & Early development & Late development & $\mathbf{N}^{0}$ days \\
\hline AntiSSEA1-/C-CONTROL & 9 & 6 & 5 & 4.7 \\
AntiSSEA1-/C+CONTROL & 8 & 8 & 7 & 5 \\
AntiSSEA1 10/C+ & 12 & 8 & 7 & 4.5 \\
AntiSSEA1 100/C+ & 11 & 11 & 9 & 4.8 \\
AntiSSEA1 1000/C+ & 10 & 9 & 9 & 4.9 \\
\hline TOTAL & $\mathbf{5 0}$ & $\mathbf{4 2 ~ ( 6 7 - 1 0 0 \% )}$ & $\mathbf{3 7 ( 5 6 - 9 0 \% )}$ & $\mathbf{4 . 7}$ \\
\hline
\end{tabular}

131 Ex-ovo dose-response study with deposition of antiSSEA1 and baby rabbit serum to the dorsal

132 side of epiblast. In all control embryos the PGCs counts were in the order of hundreds, while

133 the percentage of embryos with scarce or without PGCs were increasing with $1 / 10$ and $1 / 100$

134 concentration of antiSSEA1. The dose-response study evaluated "in toto" revealed that

135 antiSSEA1 100/C+ 1/40 was the most effective treatment destroying PGCs, because none of

136 PGCs were seen in any embryo receiving this treatment ( Table 2 and Fig 2c). 
bioRxiv preprint doi: https://doi.org/10.1101/091116; this version posted December 2, 2016. The copyright holder for this preprint (which was not certified by peer review) is the author/funder. All rights reserved. No reuse allowed without permission.

\section{immunosurgery PGCs}

Figure 2. Treated embryos. The treatment was deposited to the dorsal side of epiblast. Days of survival (2a) and Number of PGCs (2b). PGCs were counted after a complete sectioning of embryos, a total of 2,400 tissue sections were evaluated. PGCs were immunochemically marked with antiSSEA1, biotinylated anti-mouse, followed by AP conjugated streptavidin and Fast Red. Three different experiments with at least 4 embryos per treatment group. 2c) Dose-response study in top-treated embryos, the PGCs were immunochemically marked with antiSSEA1 and antimouse alexa 488 "in toto". Y-axis percentage of embryos in each treatment group. X-axis: AntiSSEA1 $(-, 1 / 10,1 / 100$ and 1/100)/Baby rabbit serum or $\mathrm{C}(-$ or + at $1 / 40)$ designed as $-/,-/+, 10 /+, 100 /+$ and $1000 /+$. Each group has at least three embryos.
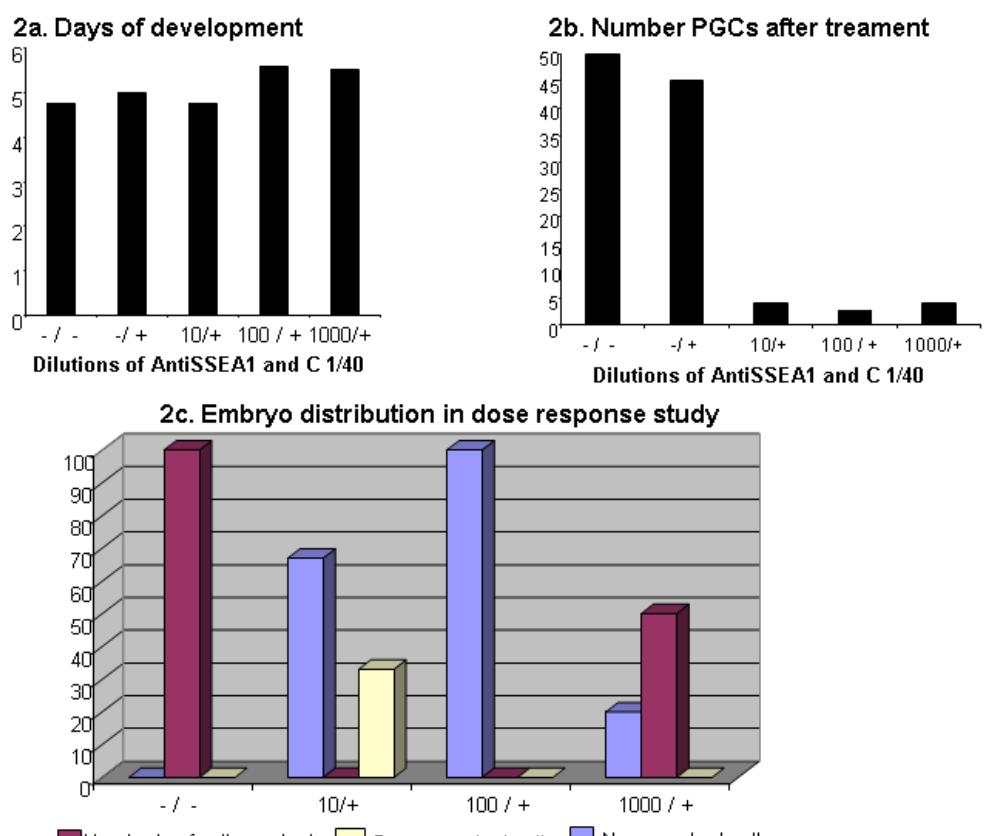

Table 2. Results of dose-response study. The treatment was sequentially deposited to the dorsal side of epiblast. The majority of the embryos overpassed day 4 of development or $22 \mathrm{HH}$ stage (Hamburger\&Hamilton's classification). None embryo showed marked PGCs in the treated group antiSSEA1 100/C+

\begin{tabular}{|c|c|c|c|c|}
\hline $\begin{array}{l}\text { Treatment } \\
\text { AntisSEAl/C }\end{array}$ & $N^{0}$ embryos & Developmental stage & Number of PGCs & $\begin{array}{c}\% \text { Embryos w/o } \\
\text { PGCs }\end{array}$ \\
\hline AntiSSEAl-/C- & 3 & $\begin{array}{l}26 \mathrm{HH} \\
28 \mathrm{HH} \\
22 \mathrm{HH}\end{array}$ & $\begin{array}{l}\text { Hundreds } \\
\text { Hundreds } \\
\text { Hundreds }\end{array}$ & 0 \\
\hline AntiSSEAl $+10 / C$ & 3 & $\begin{array}{l}29 \mathrm{HH} \\
20 \mathrm{HH} \\
23 \mathrm{HH}\end{array}$ & $\begin{array}{c}\text { None } \\
\text { None } \\
44\end{array}$ & 33 \\
\hline AntiSSEAl $+100 / \mathrm{C}$ & 4 & $\begin{array}{l}29 \mathrm{HH} \\
29 \mathrm{HH} \\
29 \mathrm{HH} \\
10 \mathrm{HH}\end{array}$ & $\begin{array}{l}\text { None } \\
\text { None } \\
\text { None } \\
\text { None }\end{array}$ & 100 \\
\hline AntiSSEAl $+1000 / \mathrm{C}$ & 6 & $\begin{array}{l}29 \mathrm{HH} \\
27 \mathrm{HH} \\
29 \mathrm{HH} \\
26 \mathrm{HH} \\
29 \mathrm{HH} \\
19 \mathrm{HH}\end{array}$ & $\begin{array}{c}\text { Hundreds } \\
\text { Hundreds } \\
\text { None } \\
\text { Hundreds } \\
\text { None } \\
\text { None }\end{array}$ & 50 \\
\hline AntisSEAl-/C- & 5 & $\begin{array}{l}29 \mathrm{HH} \\
27 \mathrm{HH} \\
24 \mathrm{HH} \\
29 \mathrm{HH}\end{array}$ & $\begin{array}{c}\text { Hundreds } \\
\text { Hundreds } \\
15 \\
\text { Hundreds } \\
\text { Hundreds }\end{array}$ & $\mathbf{0}$ \\
\hline
\end{tabular}


immunosurgery PGCs

139 Embryos treated with injections into the subgerminal space. The evaluation of embryonic

140 survival revealed that the injected treatments and transfer manipulations did not affect neither

141 embryo "early development" (67-100\%) nor "late development" (50-75\%) in any of the

142 treated groups (AntiSSEA1 100/C+100, 100/C+1000 and /C+10000 groups) compared with

143 controls (AntiSSEA1-/C- and AntiSSEA1-/C+1000), Table 3. The mean survival for injected

144 embryos (4.4 days) was not different from top-dressed ones (4.7 days; Table 3 and Fig 3a).

145 The number of PGCs detected was decreased in treated (41, 28 and 45 PGCs in AntiSSEA1

$146100 / \mathrm{C}+100,100 / \mathrm{C}+1000$ and $1000 / \mathrm{C}+10000$ groups, respectively) compared with control

147 embryos (82 and 100 PGCs in AntiSSEA1-/C- and AntiSSEA1-/C+1000, Fig 3b). The

148 maximum cytolytic activity was achieved with anti SSEA1 100/C+1000. The complement

149 alone did not show any cytolytic activity at 1/1000 dilution. Moreover, in a study of

150 complement cytotoxicity all 6 embryos injected with AntiSSEA1-/C10 developed and had a

151 high number of PGCs.

152 Unexpectedly, when antibody and complement were injected together in a single injection, 153 only half of the embryos reached "early development" and none "late development" (Table 3 154 and Fig 3a). 
bioRxiv preprint doi: https://doi.org/10.1101/091116; this version posted December 2, 2016. The copyright holder for this preprint (which was not certified by peer review) is the author/funder. All rights reserved. No reuse allowed without permission.

immunosurgery PGCs

Table 3. Embryo distribution of "early" and "late development" after subgerminal injections in chicken embryos at stage X. "Early development" 24 hours after the application of the treatment, the embryo continues to advance. "Late development" at day fourth embryos with heartbeat and vascular tree well formed.

\begin{tabular}{|c|c|c|c|c|}
\hline $\begin{array}{l}\text { Treatment } \\
\text { AntiSSEA1/complement }\end{array}$ & $\mathrm{N}^{0}$ embryos & Early development & Late development & $\mathrm{N}^{0}$ days \\
\hline AntiSSEA1-IC-CONTROL & 12 & 9 & 6 & 4.7 \\
\hline AntiSSEA1+100/C+1000 & 10 & 8 & 8 & 4 \\
\hline AntiSSEA1+100/C+100 & 7 & 6 & 4 & 3.7 \\
\hline AntiSSEA1+100/C+1000 & 4 & 4 & 4 & 5 \\
\hline AntiSSEA $1+100 / C+10000$ & 6 & 5 & 5 & 4.7 \\
\hline Cocktail & 6 & 3 & 0 & \\
\hline TOTAL & 43 & $35(67-100 \%)$ & $27(50-75 \%)$ & 4.4 \\
\hline
\end{tabular}

Figure 3. Subgerminally injected stage $X$ embryos. Days of embryo survival (3a) and Number of PGCs (3b). The PGCs were counted after sectioning of entire embryos, a total of 3,900 tissue sections were immunostained and evaluated. 3a) Days of embryo survival after sequential injections of antiSSEA1 (- or + 1/100) and C (-, 1/100, $1 / 1 \mathrm{~K}$ and $1 / 10 \mathrm{~K}$ ). Joint injection of antiSSEA.1 and baby rabbit serum (cocktail), none of embryos were developed. 3b) Number of PGCs, the maximum cytolytic activity was archived between antiSSEA1 $+/ 100-+/ 1 \mathrm{~K}$. The baby rabbit serum alone did not show any cytolytic action $(-/ 1 \mathrm{~K})$.

3a. Days of development

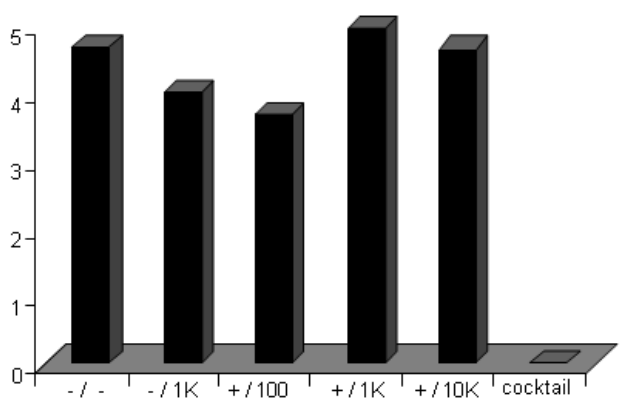

Dilutions of AntiSSEA1 (1/100) and C 3b. Number of cells

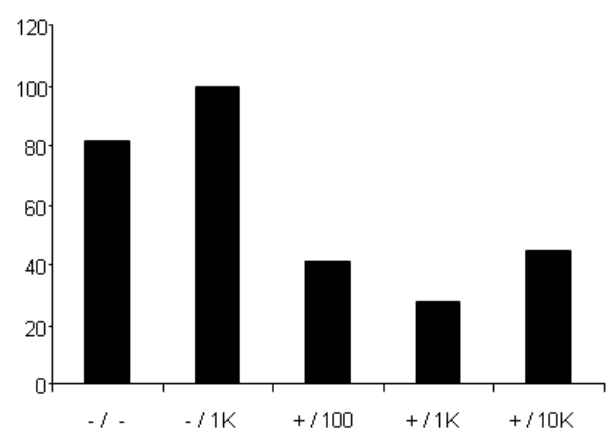

Dilutions of AntiSSEA1 (1/100) and C 
bioRxiv preprint doi: https://doi.org/10.1101/091116; this version posted December 2, 2016. The copyright holder for this preprint (which was not certified by peer review) is the author/funder. All rights reserved. No reuse allowed without permission.

immunosurgery PGCs

157

158 Immunocytochemistry and histological studies

159 Immunohistochemistry in tissue sections. In top-dressed and injected embryos, a total of 6,900

160 tissue sections were immunostained and the number of PGCs counted (Fig 4).

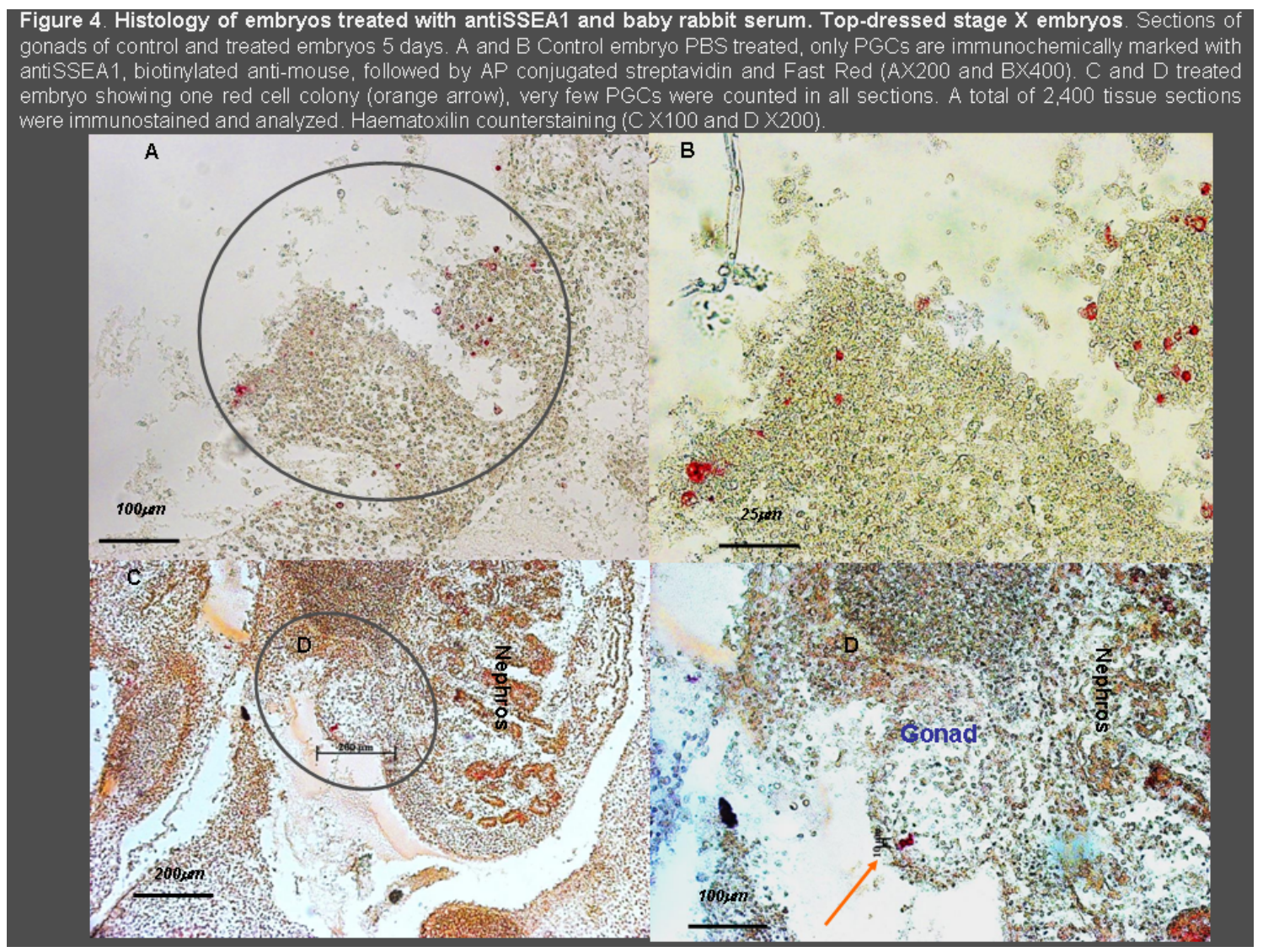

162 The data "number of PGCs" have been already presented above (Fig $2 b$ and $3 b$ ).

163 Immunohistochemistry "in toto". In order to stain PGCs the embryos needed a strong 164 permeabilization step (1\% DMSO+0.1\% triton X-100 in PBS overnight) and long periods of 165 antibodies incubations (antiSSEA1 and Ig G donkey antimouse alexa 488, with 48 and 24 166 hours at room temperature, respectively). In control embryos the presence of hundreds of 
bioRxiv preprint doi: https://doi.org/10.1101/091116; this version posted December 2, 2016. The copyright holder for this preprint (which was not certified by peer review) is the author/funder. All rights reserved. No reuse allowed without permission.

immunosurgery PGCs

167 PGCs can be visualized in Fig 5 A. In Fig 5B and 5C most of the PGCs are already in the

168 gonads but some are in their way migrating from the aorta, only PGCs were marked.

169 In some embryos of the antiSSEA1-/C+ group the immunocytohistology showed hundreds of

170 labelled cells in their gonads but the labeling was not as strong as in the antiSSEA1-/C-group

171 (Fig 5D E). The confirmation of the PGCs presence was made with a histological Alcian

172 Blue-PAS staining (Fig 5F). In contrast, none of the four treated embryos showed any PGCs

173 (Fig 6 A', B', C' and D').

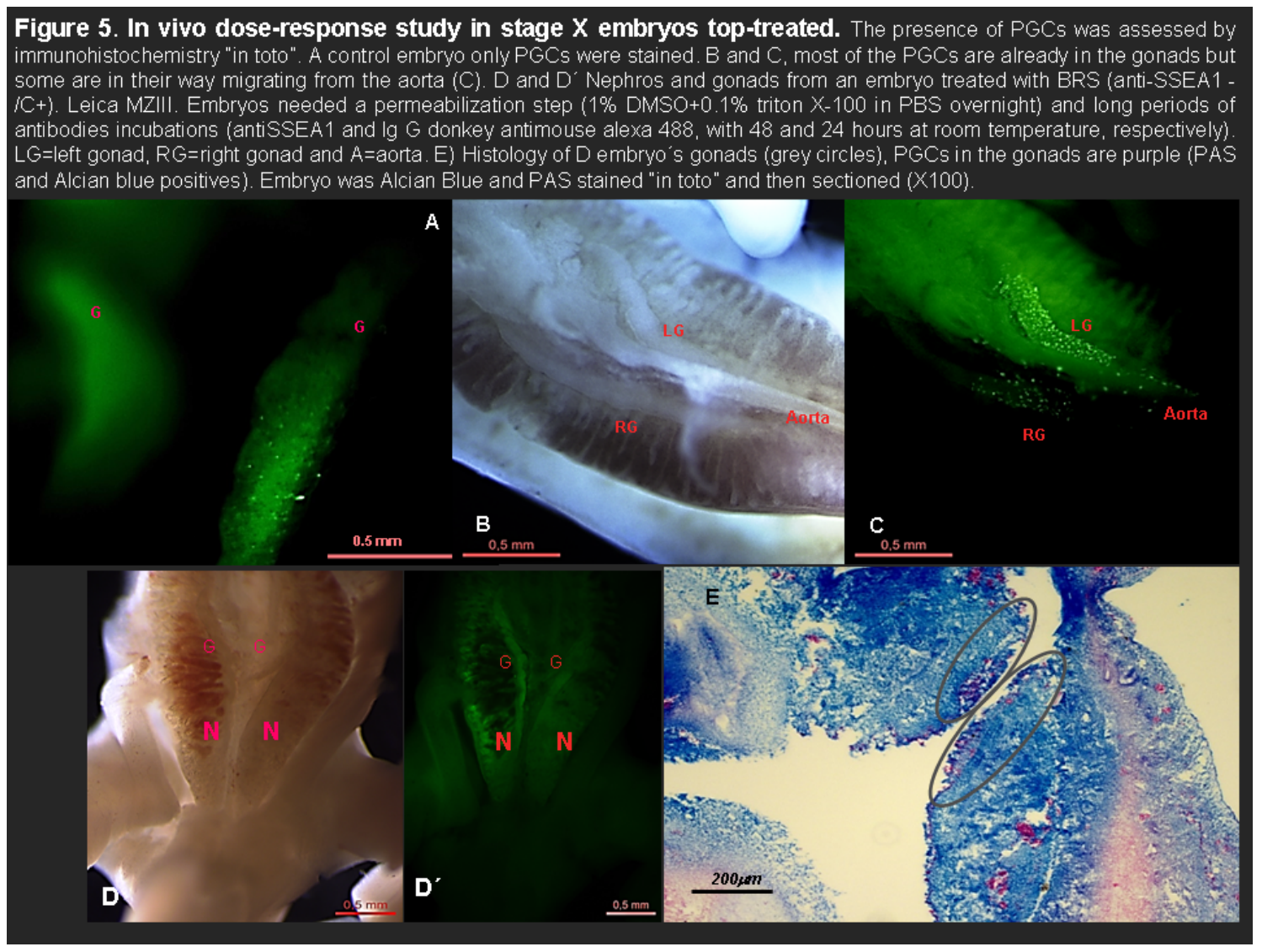


Figure 6. Treated embryos from "in vivo" dose-response study in stage X embryos top-treated. Embryo development did not progress beyond 6 days $(\mathrm{HH} 29)$. A B and $C$ treated embryos with absence of PGCs. A B C visible light and $A^{\prime}, B^{\prime}, C^{\prime}$ and fluorescence. AntiSSEA1 immunocytochemistry was made "in toto" with antimouse alexa 488. Evaluated under fluorescence stereoscope Leica MZIII. G=gonad $N=$ nephros

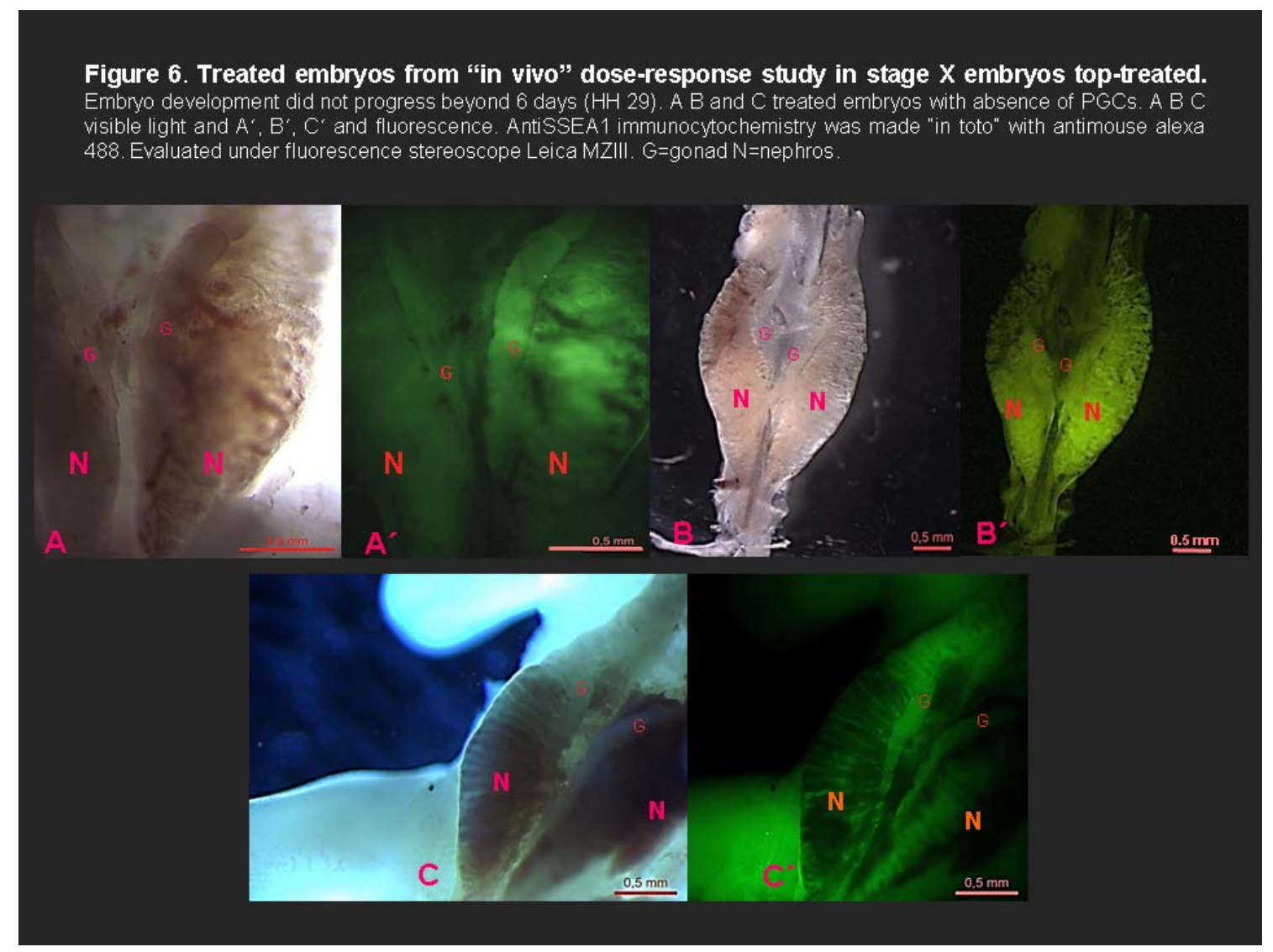

\section{DISCUSSION}

179 Our results demonstrated that immune-mediated ablation is an effective method for decimating the internal population of PGCs when preparing recipient chick embryos for germ

181 line chimera construction. Germ cell numbers can be substantially reduced while embryo 182 development is not affected. Treatment, dose and route had an impact on effectiveness and on 183 survivability.

"In vivo" top-dress application, directly on the germinal disc, is, by far, the best assayed. No

185 instrumentation is needed (stereomicroscope or micro injector) and it is the most gentle on the

186 embryo. The response, in terms of PGCs numbers in the gonads, was dose dependent. Almost

187 a complete ablation was achieved using antiSSEA1 and complement at 1/100 and 1/40 
immunosurgery PGCs

188

dilutions, respectively. These doses are coincident with our results obtained in the "in vitro" competition studies with SBRCs. We must emphasize that the duration of embryonic development and the organic structures were normal. There was a concern that this form of administration could be insufficient, as the molecules of antiSSEA1 and complement must cross not only the vitelline membranes but also the blastoderm itself. Gerhart et al. were able to ablate two lineages of epiblast cells expressing skeletal muscle (MyoD) and neuronal (NeuroM) surface antigens (Gerhart et al. 2008; Gerhart et al. 2010). Supporting in part, our studies in using this route, since PGCs are concentrated on the hypoblast at stage X.

This was the reason why direct treatment injection on the subgerminal space, that is, immediately below the hypoblast, was also assayed. We expected this route would be more effective on PGCs but also more damaging on the embryo because of repeated puncture of the vitelline membrane. As anticipated, relative to top-dressing, sequential subgerminal application required less complement (antiSSEA1/100 plus C 1/1000), to yield an equally extensive PGCs ablation; survival of the embryos was, however, not impaired. There could be two reasons why less complement is needed when injected; first, the effective complement concentration around the target PGCs should be undoubtedly higher, as losses due to diffusion are minor; second, the antiSSEA1 labelling on the target cells is more extensive, since the injected antibody is not washed away after a short reaction time as when top-dressed.

In both strategies, the natural Ig and innate complement system present in BRS could be implicated (Gerencer et al. 1998). The most probable mechanism would be that once antiSSEA1 is bound to the outer Gal $\beta$ (1-4), Fuc $\alpha(1-3)$-GlcNAc $\beta 1-R 4$ of PGCs, the rabbit innate complement system will consequently induce PGCs cytolysis by Complement Classical Pathway activation $\left(\mathrm{C}_{1 q}\right)$. Gerhart's results and the fact that in stage $\mathrm{X}$ embryos, neither complement enzymes nor IgM are present, support this mechanism. AntiSSEA1 has been 
immunosurgery PGCs

212 frequently used to enrich PGCs isolates (Etches 1998 and Mozdziak 2006) although other 213 antibodies have also been successful, as EMA-1, NC-1 and VASA. The later could be an 214 optimum choice because of its specificity for germ line cells, as long as a good chicken 215 antiVASA would be available.

216 We assayed a third administration strategy, joint injection of antiSSEA1 plus BRS into the 217 subgerminal space, in case the double injection proved too detrimental to embryo viability. 218 An unforeseen and remarkable disruption was observed on germinal disc development 219 following injection of the antiSSEA1-BRS mixture. It suggests that a massive, untargeted 220 cytolytic activity was developed that damaged several embryonic cell populations and structures. The only report on simultaneous use of antibody and serum (premixed before administration) "in vivo" is that of Takami et al. (2006) when treating a CNS lymphoma with rituximab, after previous treatment failures applying the antibody alone intraventricularly 224 (Schulz et al. 2004). Generally, when the antibody-complement complex is used to direct a cytolysis over certain cell populations, the "modus operandi" is: the cells are first exposed to the antibody and, later on, the complement is applied to induce the lysis of only those cells previously targeted (Gerhart et al.2008, Gerhart et al. 2010, Chen and Melton 2007). Maybe other enzymes besides $\mathrm{Cq} 1$ of the complement system could be activated through the Lectin pathway. Several types of lectins present in serum have been studied, among them, mannosebinding lectins (bind to mannose) and ficolins (bind to GlcNAc or fucose). The latter need IgM to activate Lectin pathway (Endo et al. 2015). Humoral ficolins present in BRS could very well bind to IgM (antiSSEA1) when mixed and subsequently activate the complement enzymes $\left(\mathrm{C}_{4}\right.$ and $\left.\mathrm{C}_{2}\right)$, which in turn, will destroy indiscriminately blastodermal cells.

234 Supporting our hypotesis, Lei et al. (2015) have described a novel IgM-H-Ficolin complement pathway which ablates "in vitro" allogenic human cancer cells. Glycans covering blastodermal cells, as well as cancer cells, have GlcNAc and fucose (Endo et al. 2015 and Lei 
immunosurgery PGCs

237 et al. 2015). In stage $\mathrm{X}$ chick embryos the glycocalyx of blastodermal cells and PGCs are

238 richer in GlcNAc than in mannose (author unpublished observations). Taken together all we

239 suggest a possible implication of IgM-ficolins complexes in this massive destruction.

240 However, obviously the question of why antibody-complement together strongly increased

241 cytolitic efects needs to be further investigated.

242 The use of monoclonal antibodies and complement is one of the most promising therapies in 243 cancer. However, in long term treatments with specific antibodies, some tumours produce 244 their own complement and others modulate the complement regulators resulting in the 245 inhibition of the innate complement. As far as we know, premixing of exogenous complement 246 and monoclonal antibody has not been reported as a strategy to boost antibody therapeutical 247 effects. Our results are supported by the reported treatment of primary central nervous system 248 lymphoma in humans using Rituximab (monoclonal antibody against primary lymphoma 249 cells) and exogenous complement (Nishimura et al. 2003). Therefore, the mixture of 250 antibody-complement previously to its local application could be very useful to treat large established tumours from which available antibodies exist and also to potentiate the antibody 252 efficiency.

253 On the other hand, the lack of cytolytic response in our control, demonstrates that complement 254 alone, even when directly injected into the subgerminal space at the highest concentration 255 ( $\mathrm{C}+1 / 10$ dilution), is not cytotoxic for the developing stage $\mathrm{X}$ embryo: it failed to reduce the 256 endogenous PGCs population and it did not affect embryo viability at all.

257 Therefore, two protocols successfully produced lysis of the primordial germ cells by specific 258 cell labelling with antibody followed by heterologous serum with innate complement system 259 present in BRS. Dress-on application is simpler and faster than subgerminal injection while 260 equally effective, although larger quantities of reagents are needed. Both methods are capable 
immunosurgery PGCs

261 of producing an almost complete ablation of the germline cells in chicken embryos with a

262 high efficiency without damaging other embryonic structures at stage X embryos.

264 MATERIALS and METHODS

265 Egg source

266 Freshly fertilized laid chicken eggs were obtained from Cobb SA (Alcalá de Henares, Madrid,

267 Spain). Housing and management of the laying hens (Gallus gallus, Linn) comply with 268 welfare and sanitary EU standards.

"In vitro" cytolysis of avian blastoderm cells

Competition tests of dispersed blastodermal cells with haemolytic system (HS). The optimal dilution of the available complement systems was established in a complement assay with baby rabbit serum (BRS) and haemolytic system (HS; SRBC and haemolysin in gelatine-

273 Veronal buffer containing $\mathrm{Ca}^{2+}$ and $\left.\mathrm{Mg}^{2+}, \mathrm{SRBCs}\right)$. All reactives were generously supplied by Margarita López Trascasa, Hospital La Paz, Madrid Spain. Indirect estimation of blastoderm cytolysis was made using SRBCs, HS and blastoderm cells in competition assays. Maximum haemolysis was induced by addition of distilled water to $\mathrm{HS}$. The $\mathrm{CH}_{50}$ was established as the range of those dilutions of BRS when haemolytic action was exhausted, and SRBCs started to settle down in round-bottom ELISA plates.

A total of 32 blastoderms were isolated from embryonated eggs at oviposition and disaggregated with repeated pipetting for three competitive studies. First, the blastoderm cell

281 suspensions of ten stage $\mathrm{X}$ embryos (300 $\mu \mathrm{l}$ approx $10^{7}$ cells $\left./ \mathrm{ml}\right)$ were incubated in assay

282 tubes with monoclonal antibody antiSSEA1 obtained as concentrate from the Developmental

283 Studies Hybridoma Bank (1/100 and 1/1000) during 45 minutes at $37^{\circ} \mathrm{C}$ in a water bath. Next, 
immunosurgery PGCs

284

285

286

BRS $(1 / 10 ; 1 / 100 ; 1 / 1000$ and 1/10000) plus HS were added and, after incubation for an additional hour at $37^{\circ} \mathrm{C}$ in a water bath, the reaction cocktail was centrifuged $1000 \mathrm{~g}$ for 10 minutes and the supernatant was transferred to a multi-well plate where absorbance at $405 \mathrm{~nm}$ was recorded. At the end of the second incubation, each reaction tube was evaluated for SRBC sedimentation: a reddish sediment in the tube reveals incomplete haemolysis since the complement in the reaction mix has been exhausted. Conversely, absence of SRBC sediment denotes excess complement activity in the mix. The degree of haemolysis was measured as the absorbance of the supernatants at $405 \mathrm{~nm}$. Saturation curves revealed that $\mathrm{CH}_{50}$ was reached after adding BRS between a range of 1/10 -1/100 dilutions.

Next, a total of 26 entire blastoderms were isolated for the evaluation of cell viability described previously (Gerhart et al. 2008). In brief, each isolated embryo was placed in a well with cell culture medium M199 in four experiments following previously described culture conditions (Lopez-Diaz et al. 2016). Next, the blastoderms were challenged to antiSSEA1 (1/100 and $1 / 1000)$ incubated during 45 minutes at $37^{\circ} \mathrm{C}$ and then to BRS (1/50). After incubation for an additional hour at $37^{\circ} \mathrm{C}$, the evaluation of cell destruction was made adding 4\% trypan blue $(4 \mu 1)$. Control blastoderms were incubated with only M199 or BRS+M199.

\section{Ex-ovo treatments applied to stage $X$ embryos and incubated in surrogated egg shells following Perry's system II}

Deposition of antiSSEAI and baby rabbit serum to the dorsal side of epiblast. Embryonated chicken eggs at ovoposition (stage X) were cleaned with alcohol or with a solution of sodium hypochlorite for 30 or 60 minutes before use. The eggs content was poured on sterile Petri dishes to expose and manipulate the embryos following Gerhart's procedure (Gerhart et al. 2008) with some variations. Briefly, the albumen covering the germinal disc was cleaned with sterile cellulose tissues until a well-marked hollowness appeared. Once the germinal discs 
immunosurgery PGCs

were free from albumen, $100 \mu \mathrm{l}$ of antiSSEA1 $(1 / 10,1 / 100$ and 1/1000) were pipetted on top of the germinal disc and covered with a piece of parafilm. The treated embryos were incubated in an oven at $37^{\circ} \mathrm{C}$ saturated with moisture for 1 hour. The excess of unbound monoclonal antibody was washed away three times with PBS and BRS was immediately topdressed on the blastoderm. Baby rabbit serum (diluted $1 / 40$ in PBS $+0.1 \%$ skim milk) was used as a source of complement because it only has the innate complement system (C) and natural immunoglobulins, lacking immune $\operatorname{IgG}$ and $\operatorname{IgM}$ (Gerencer et al. 1998). The blastoderm was covered with parafilm and incubated for another hour in the same conditions. After washing the BRS, the contents of eggs were transferred to surrogate egg shells following Perry's system II (Perry, 1988). A total of 50 embryos were evaluated and histologically studied from three different experiments with at least 4 embryos per treatment group (antiSSEA1 -/C-; antiSSEA1 10/C+, antiSSEA1 100/C+, antiSSEA1 1000/C+ and antiSSEA1 -/C+).

Treatment with two sequential injections into the subgerminal space. Embryos were injected $\mu \mathrm{l}$ of antiSSEA1 (1/100) was injected with micropipettes using a pneumatic fluid microinjector (Injectmatic, Geneva, $\mathrm{CH}$ ). The treated embryos were incubated in an oven at $37{ }^{\circ} \mathrm{C}$ saturated with moisture for 1 hour. Later, BSR was injected at different dilutions $(1 / 100,1 / 1000$ and $1 / 10000)$. After the last injection the contents of eggs were transferred to surrogate egg shells. A total of 43 embryos were evaluated from three different experiments with at least 4 embryos per treatment group (antiSSEA1 -/C-, antiSSEA1 100/C100, antiSSEA1 100/C+1000, antiSSEA1 100/C+10000 and antiSSEA1 -/C+1000). In order to rule out a possible direct cytotoxic effect of BRS, a study was undertaken injecting subgerminally 
immunosurgery PGCs

Treatment with a single injection into the subgerminal space. Six embryos were injected into

334 the subgerminal space as indicated above, except that antiSSEA1 and BRS were jointly

335 applied in a single injection (antiSSEA1 10/C+10).

336 Evaluation of embryo development. Everyday "embryo development" was checked and

337 recorded. Embryo development was recorded as "early development" on progress, if next day

338 after the application of the treatment, germinal disc showed normal growth and no yolk

339 leaking was seen. On third day "late development" was recorded as normal when the vessels

340 were formed and the heart was beating. Embryos were incubated at least until 5-6 day in an

341 egg incubator (Octagon) on system II (Perry 1988). Once the incubation was over or the

342 embryo development stopped, the embryos were dissected, fixed and conserved in methanol

$34370 \%$ until histological and immunohistological studies were undertaken.

\section{Immunocytochemistry and histological studies}

345 Top-dressed and sequential injections into the subgerminal space embryos. The presence of

346 PGCs was assessed by an alkaline phosphatase (AP) immunocytochemical detection system

347 using antiSSEA1 (DSHB; Iowa City, IA, U.S.A.). Briefly, embryos were fixed in Bouin's

348 solution overnight, embedded in parafine and entirely cut with microtome into tissue sections

349 of $10 \mu \mathrm{m}$. A total of 6,300 tissue sections were analyzed (a mean of 100 tissue sections per

350 embryo). To minimize nonspecific binding, the tissue slices were treated for 3 hours with $3 \%$

351 BSA and $0.1 \%$ triton X-100 in PBS before immunostaining. The optimal concentration of

352 each antibody was selected based on the results of preliminary experiments (1/300 for

353 antiSSEA1 and anti-mouse). Tissues were incubated for $24-48$ hours with the primary

354 antibody at $4^{\circ} \mathrm{C}$ and subsequently reacted for 24 hours each with biotinylated anti-mouse

355 (Sigma B0529, for monoclonal first antibody) followed by AP conjugated streptavidin (Sigma

356 E2636). Fast Red was used as substrate chromogen. To avoid interference by the potential 
immunosurgery PGCs

357 endogenous activity of AP, the tissues were treated with $0.02 \mathrm{M}$ levamisole or heat inactivated 358 at $70^{\circ} \mathrm{C}$ for 30 minutes.

Dose-response study. In the dose-response study the number of PGCs was evaluated "in toto" embryos by immunohistochemistry. Briefly, embryos were fixed in $4 \%$ paraformaldehyde in PBS overnight at $4{ }^{\circ} \mathrm{C}$, permeabilized using $1 \%$ DMSO and $0.1 \%$ triton $\mathrm{X}-100$ in PBS overnight and unspecific binding blocked at $4{ }^{\circ} \mathrm{C}$ overnight with $3 \% \mathrm{BSA}$ and $0.1 \%$ triton $\mathrm{X}$ 100 in PBS before immunostaining. The presence of PGCs was assessed by Ig G donkey antimouse alexa 488 ( 24 hours at room temperature, Invitrogen) and antiSSEA1 as primary antibody (48 hours of incubation). This immunohistochemistry allowed us a clear identification of PGCs with absent fluorescent background. The nephros and gonads were dissected and the number of PGCs twice counted under a stereoscope LEICA MZIII and an inverted fluorescence microscope by two people (Nikon, Eclipse TE300; Tokyo, Japan, fitted with a H910104A, TE-FM Epi-Fluorescence Lamp). The results were classified as: no cells = none PGCs marked, countable cells = less than 100 marked PGCs and uncountable cells $=$ hundreds of PGCs were marked. In order to confirm that PGCs were marked, other histological studies were made like PAS. In some embryos with weak fluorescece labelled PGCs, specially all those treated only with complement, the gonads were stained with Alcian Blue and PAS (Merk Germany 1.016460001) following the manufacturer's instructions. PGCs are Alcian Blue and PAS positive which gives a unique purple color at $\mathrm{HH} 27$ developmental stage (5 days).

\section{Acknowledgements}

The authors acknowledge the valuable support of Dra Capitolina Díaz Martínez, President of AMIT (Asociación de Mujeres Investigadoras y Tecnólogas). The valuable help of Soraya Martínez-Alcocer and Diana González-Chamorro for histological processing is gratefully 
immunosurgery PGCs

381 acknowledged. This study was partly supported by the grant AGL 2009E06345-MICINN

382 (Spain).

383 The monoclonal antibody antiSSEA1 developed by Solter and Knowles was obtained

384 from the Developmental Studies Hybridoma Bank developed under the auspices of the

385 NICHD and maintained by The University of Iowa, Department of Biology, Iowa City, IA

38652242.

387 
immunosurgery PGCs

\section{REFERENCES}

1. Aige-Gil, V. and Simkiss, K. 1991. Sterilisation of avian embryos with busulphan. Research in Veterinary Science. 50: 139-144.

2. Bresler, M., Behnam, J., Luke, G., and Simkiss, K. 1994. Manipulations of germ-

3. Carsience, R., Clark, M., Verrinder Gibbins, A., Etches, R. 1993. Germline chimeric chickens from dispersed donor blastodermal cells and compromised recipient embryos. Development. 117, 669-675.

4. Chen, A. E. and Melton, D.A. 2007. Derivation of human embryonic stem cells by immunosurgery. J Vis Exp. (10):574. doi: 10.3791/574. Epub 2007 Dec 13.

5. Dubois, R. 1969. Données nouvelles sur la localisation des cellules germinales primordiales dans le germe non incubé de poulet. C. R. Acad. Sci. 269, 205-208.

6. Endo Y., Matsushita, M., Fujita, T. 2015. New insights into the role of ficolins in the lectin pathway of innate immunity. Int Rev Cell Mol Biol. 316:49-110. doi: 10.1016/bs.ircmb.2015.01.003. Epub 2015 Feb 20.

7. Etches R. Methods for selecting germ-line competent cells in chicken embryos, and the use of the cells in the production of chimeras. 1998. International Patent Classification. C12N 5/06, A01K 67/027.

8. Gerencer, M., Barrett, PN., Kistner, O., Mitterer, A., Dorner, F. 1998. Natural IgM antibodies in baby rabbit serum bind high-mannose glycans on HIV type 1 glycoprotein 120/160 and activate classic complement pathway. AIDS Res Hum Retroviruses. 14(7):599-605.

9. Gerhart, J., Neely, C., Pfautz, J., George-Weinstein, M. 2008. Tracking and ablating subpopulations of epiblast cells in the chick embryo. Biol Proced Online. Sep 1;10:74-82. doi: 10.1251/bpo145. 
immunosurgery PGCs

10. Gerhart, J., Pfautz, J., Neely, C., Elder, J., DuPrey, K., , Menko, A.Sue., Knudsen K. and George-Weinstein, M. 2010. Noggin producing, MyoD-positive cells are crucial for eye development. Dev Biol. 2009 December 1; 336(1): 30-41.

11. Hemsworth, B. N., Jackson, H. 1963. Effect of busulphan on the developing ovary in the rat. J Reprod Fert. 6: 229-233.

12. Kalfayan , B., and Kidd, J. G. 1953. Structural changes produced in Brown-Pearce carcinoma cells by means of a specific antibody and complement. J Exp Med.1953 Jan;97(1):145-62.

13. Kino, K. B., Pain, B., Leibo, M., Cochran, M., Clark, M. E., Etches, R. J. (1997). Production of chicken chimeras from injection of frozen-thawed blastodermal cells. Poult. Sci. 76:753-760.

14. Kuwana, T. and Fujimoto, T. 1984. Locomotion and scanning electron microscopic observations of primordial germ cells from the embryonic chick blood in vitro. Anat. Rec. 209, 337-34.

15. Lei, X., Liu, C., Azadzoi, K., Li, C., Lu, F., Xiang, A., Sun, J., Guo, Y., Zhao, Q., Yan Z., Yang, J. 2015. A novel IgM-H-Ficolin complement pathway to attack allogenic cancer cells in vitro. Scientific reports | 5: 7824 | DOI: 10.1038/srep07824.

16. Lia, C-H., Kagamib, H., Matsuib, K., Onob, T. 2001. Restriction of proliferation of primordial germ cells by the irradiation of Japanese quail embryos with soft X-rays. Comparative Biochemistry and Physiology. Part A 130 133_140.

17. Lopez-Diaz, Mariacruz, Bujan-Varela, J., Cadorniga-Valiño, C. 2016. Viable pluripotent chick blastodermal cells can be maintained long term in an alkaline defined medium. In Vitro Cellular \& Developmental Biology - Animal (9989). DOI: 10.1007/s11626-015-9989-5. 
immunosurgery PGCs

18. Macor, P., and Tedesco, F. 2007. Complement as effector system in cancer immunotherapy. Immunol Lett. Jul 31; 111(1):6-13. Epub 2007 May 29.

19. Maeda, T., Clark, M. E., Etches, R. J. 1998. Mortality, size of the gonads, and

20. Mozdziak, P. E., Wysocki, R., Angerman-Stewart, J., Pardue, S. L., and Petitte, ultrastructure of primordial germ cell in chick embryos treated with $\gamma$-irradiation or injected with donor cells. Poult. Sci. 77:905-907. J. N. 2006. Production of Chick Germline Chimeras from Fluorescence-Activated Cell-Sorted Gonocytes. Poultry Science. 85:1764-1768.

21. Muniesa, P. and Dominguez, L. 1990. A morphological study of primordial germ cells at pregastrular stages in the chick embryo. Cell Differ Dev. Aug; 31(2):105-17.

22. Naito M., Harumi T., Kuwana T. 2015. Long-term culture of chicken primordial germ cells isolated from embryonic blood and production of germline chimaeric chickens. Anim Reprod Sci.Feb; 153:50-61. doi: 10.1016/j.anireprosci.2014.12.003. Epub 2014 Dec 24.

23. Nakamura, Y., Usui, F., Miyahara, D., Mori, T., Ono, T., Kagami, H., Takeda, K., Nirasawa, K., Tagami, T. 2012. X-irradiation removes endogenous primordial germ cells (PGCs) and increases germline transmission of donor PGCs in chimeric chickens. J Reprod Dev. 58(4):432-7. Epub 2012 Apr 13.

24. Nishimura, R., Goto, Y., Maeba, H. et al. 2003. Simultaneous supply of human complement required for an effective treatment of CNS lymphomas with rituximab: therapeutic experimental evidence. Blood. 102: 4958a.

25. Perry M. M. 1988. A complete culture system for the chick embryo. Nature. 331, 70 72 (07 January 1988). 
immunosurgery PGCs

26. Petitte, J. N., Clark, M. E., Liu, G., Gibbins, A. M. V., Etches, R. J. 1990. Production of somatic and germline chimeras in the chicken by transfer of early blastodermal cells. Development. 108,185-189.

27. Reynaud, G. 1977. Action du Busulphan sure la lignee germinale de l'embryon de poulet. Bull. Soc. Zool. France 102, 41.

28. Rogers, L. M., Veeramani, S., We iner, G. J. 2014. Complement in monoclonal antibody therapy of cancer. Immunol Res. Aug;59(1-3):203-10. doi: 10.1007/s12026014-8542-z.

29. Schulz, H., Pels, H., Schmidt-Wolf, I., Zeelen, U., Germing, U., Engert, A. 2004. Intraventricular treatment of relapsed central nervous system lymphoma with the antiCD20 antibody rituximab. Haematologica. 89: 753-4.

30. Song, Y., D'costa S., Pardue S. L., and Petitte J. N. 2005. Production of Germline Chimeric Chickens Following the Administration of a Busulfan Emulsion. Molecular Reproduction and Development. 70:438-444.

31. Solter D. and Knowles B. B. 1975. Immunosurgery of mouse blastocyst. Proc Natl Acad Sci U S A. 1975 Dec; 72(12): 5099-5102.

32. Speksnijder, G., and Ivarie, R. 2000. A Modified Method of Shell Windowing for Producing Somatic or Germline Chimeras in Fertilized Chicken Eggs. Poultry Science. 79:1430-1433.

33. Stern, C.D. 1991. The sub-embryonic fluid of the egg of the domestic fowl and its relationship to the early development of the embryo. In: Avian incubation. (ed. S.G. Tullett) London: Butterworths. pp. 81-90.

34. Swift, H. M. 1914. Origin and early history of the primordial germ-cells in the chick. Am J Anat. U S A. 15:486. 
immunosurgery PGCs

35. Takami, A., Hayashi, T., Kita, D., Nishimura, R., Asakura, H., Nakao, S. 2006.

Treatment of primary central nervous system lymphoma with induction of complement dependent cytotoxicity by intraventricular administration of autologousserum-supplemented rituximab. Cancer Sci. January 2006 vol. 97 no. 1 | 81 .

36. van de Lavoir, M.C., Diamond, J.H., Leighton, P.A., Mather-Love, C., Heyer, B.S., Bradshaw, R., Kerchner, A., Hooi, L.T., Gessaro, T.M., Swanberg, S.E., Delany, M.E., Etches, R.J. 2006. Germline transmission of genetically modified primordial germ cells. Nature. Jun 8; 441(7094):766-9.

37. Whyte, J.; Glover, J.; Woodcock, M.; Brzeszczynska, J.; Taylor, L.; Sherman, A.; Kaiser, P.; McGrew, M. 2015. FGF, Insulin, and SMAD Signaling Cooperate for Avian Primordial Germ Cell Self-Renewal. In: Stem Cell Reports, 01.11.

38. Wiemann, B., Starnes, C.O. 1994. Coley's toxins, tumor necrosis factor and cancer research: a historical perspective. Pharmacol Ther. 64:529-564. 
immunosurgery PGCs

498

499

500

501

502

503

504

505

506

507

508

513

514

515

516

517

518

519

520

521

FIGURE LEGENDS

\section{Figure 1. 1a Saturation curve. Competition test with dispersed blastodermal cells and}

anti SSEA1 1/100. Haemolysis absorbance of sheep red blood cell (SBRC y-axis) with decreasing concentrations of baby rabbit serum (BRS) as a complement source (x-axis), without antiSSEA1 (yellow line) and with antiSSEA1 1/100 (blue line). When blastodermal cells and antiSSEA1 were present the saturation was reached and the $\mathrm{CH} 50(\mathrm{Kd})$ was between 1/10 and 1/100 dilutions of BRS. Blastoderm cell suspensions from ten stage X embryos were used in each saturation curve. 1b. Deposition of antiSSEA1 and baby rabbit serum to the dorsal side of epiblast and evaluation of cellular lysis with trypan blue. Chicken embryos stage X (Ax4 and B x200), A) Control embryo treated with PBS and trypan blue exposed, none cell was stained by trypan blue (stereoscope Leica MZIII) B) Zona pellucida of one embryo challenged with antiSSEA1 and baby rabbit serum, there are blue cells stained (NIKON, Eclipse TE300, inverted microscope). C) Deposition of the treatment to the dorsal side of epiblast. D) 24 hours embryo, developmental stage referred in the manuscript as "early development".

\section{Figure 2. Treated embryos. The treatment was deposited to the dorsal side of epiblast.}

Days of survival (2a) and Number of PGCs (2b). PGCs were counted after a complete sectioning of embryos, a total of 2,400 tissue sections were evaluated. PGCs were immunochemically marked with antiSSEA1, biotinylated anti-mouse, followed by AP conjugated streptavidin and Fast Red. Three different experiments with at least 4 embryos per treatment group. 2c) Dose-response study in top-treated embryos, the PGCs were immunochemically marked with antiSSEA1 and antimouse alexa 488 "in toto". Y-axis percentage of embryos in each treatment group. X-axis: AntiSSEA1 (-, 1/10, 1/100 and 
immunosurgery PGCs

522 1/100)/Baby rabbit serum or $\mathrm{C}(-$ or + at $1 / 40)$ designed as $-/-,-/+, 10 /+, 100 /+$ and 1000/+.

523 Each group has at least three embryos.

525 Figure 3. Subgerminally injected stage $\mathbf{X}$ embryos. Days of embryo survival (3a) and

526 Number of PGCs (3b). The PGCs were counted after sectioning of entire embryos, a total of

5273,900 tissue sections were immunostained and evaluated. 3a) Days of embryo survival after

528 sequential injections of antiSSEA1 $(-$ or $+1 / 100)$ and $C(-, 1 / 100,1 / 1 \mathrm{~K}$ and $1 / 10 \mathrm{~K})$. Joint

529 injection of antiSSEA1 and baby rabbit serum (cocktail), none of embryos were developed.

530 3b) Number of PGCs, the maximum cytolytic activity was archived between antiSSEA1

$531+/ 100-+/ 1 \mathrm{~K}$. The baby rabbit serum alone did not show any cytolytic action $(-/ 1 \mathrm{~K})$.

Figure 4. Histology of embryos treated with antiSSEA1 and baby rabbit serum. Top-

dressed stage $\mathbf{X}$ embryos. Sections of gonads from control and treated embryos (5-days). A

and B Control embryo PBS treated, only PGCs are immunochemically marked with

antiSSEA1, biotinylated anti-mouse, followed by AP conjugated streptavidin and Fast Red

(AX200 and BX400). C and D treated embryo showing one red cell colony (orange arrow),

very few PGCs were counted in all sections. A total of 2,400 tissue sections were immunostained and analyzed. Haematoxilin counterstaining (C X100 and D X200).

Figure 5. In vivo dose-response study in stage $\mathrm{X}$ embryos top-treated. The presence of

PGCs was assessed by immunohistochemistry "in toto". A control embryo only PGCs were

543 stained. B and C, most of the PGCs are already in the gonads but some are in their way

544 migrating from the aorta (C). D and $\mathrm{D}^{\prime}$ Nephros and gonads from an embryo treated with

545 BRS (anti-SSEA1 -/C+). Leica MZIII. Embryos needed a permeabilization step (1\%

546 DMSO+0.1\% triton X-100 in PBS overnight) and long periods of antibodies incubations 
immunosurgery PGCs

547 (antiSSEA1 and Ig G donkey antimouse alexa 488, with 48 and 24 hours at room temperature,

548 respectively). LG=left gonad, RG=right gonad and A=aorta. E) Histology of D embryo's

549 gonads (grey circles), PGCs in the gonads are purple (PAS and Alcian blue positives).

550 Embryo was Alcian Blue and PAS stained "in toto" and then sectioned (X100).

Figure 6. Treated embryos from "in vivo" dose-response study in stage X embryos top-

treated. Embryo development did not progress beyond 6 days (HH 29). A B and C treated

embryos with absence of PGCs. A B C and A', B', $\mathrm{C}^{\prime}$ visible light and fluorescence.

AntiSSEA1 immunocytochemistry was made "in toto" with antimouse alexa 488. Embryos

evaluated under fluorescence stereoscope Leica MZIII. G=gonad N=nephros.

Table 1. Embryos distribution of "early" and "late development" when the treatment was deposited to the dorsal side of epiblast at stage X. "Early development" 24 hours after the application of the treatment, the embryo continues to advance. "Late development" at day fourth embryos with heartbeat and vascular tree well formed.

Table 2. Results of dose-response study. The treatment was sequentially deposited to the dorsal side of epiblast. The majority of the embryos overpassed day 4 of development or 22 HH stage (Hamburger\&Hamilton's classification). None embryo showed marked PGCs in the treated group antiSSEA1 100/C+.

Table 3. Embryo distribution of "early" and "late development" after subgerminal injections in chicken embryos at stage $\mathbf{X}$. "Early development" 24 hours after the 570 application of the treatment, the embryo continues to advance. "Late development" at day fourth embryos with heartbeat and vascular tree well formed. 
bioRxiv preprint doi: https://doi.org/10.1101/091116; this version posted December 2, 2016. The copyright holder for this preprint (which was not certified by peer review) is the author/funder. All rights reserved. No reuse allowed without permission.

immunosurgery PGCs

\section{$574 \quad$ Competing interests}

575 The authors declare no competing or financial interests.

\section{Role of the founding source}

577 This study was supported by the grant AGL 2009E06345-MICINN (Spain). 